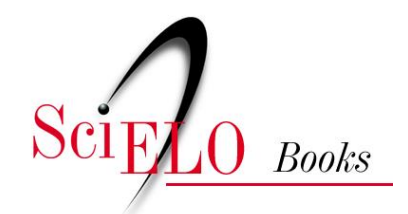

\title{
Baudelaire e Belzebu
}

\author{
Larissa Drigo Agostinho
}

AGOSTINHO, LD. Baudelaire e Belzebu. In MAGALHÃES, ACM., et al., orgs. O demoníaco na literatura [online]. Campina Grande: EDUEPB, 2012. pp. 113-123. ISBN 978-85-7879-188-9. Available from SciELO Books <http://books.scielo.org>.

\section{(c) (1) @()}

All the contents of this work, except where otherwise noted, is licensed under a Creative Commons Attribution-Non Commercial-ShareAlike 3.0 Unported.

Todo o conteúdo deste trabalho, exceto quando houver ressalva, é publicado sob a licença Creative Commons Atribuição Uso Não Comercial - Partilha nos Mesmos Termos 3.0 Não adaptada.

Todo el contenido de esta obra, excepto donde se indique lo contrario, está bajo licencia de la licencia Creative Commons Reconocimento-NoComercial-CompartirIgual 3.0 Unported. 


\title{
Baudelaire e Belzebu
}

\author{
Larissa Drigo Agostinho (Paris IV-Sorbonne) $)^{1}$
}

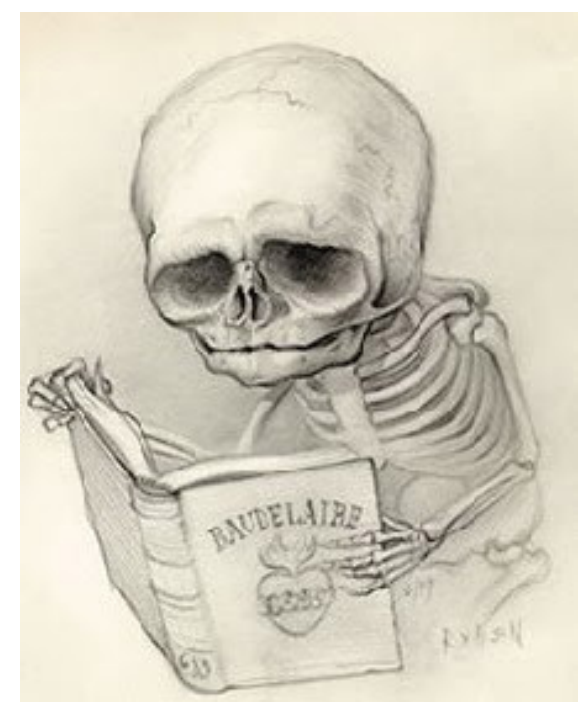

Propomos neste artigo discutir o significado do satanismo de Baudelaire com relação ao seu tempo e a poesia do primeiro romantismo francês. Isto significa discutir o significado do satanismo de Baudelaire com relação ao imaginário católico do primeiro romantismo.

A primeira geração de poetas românticos franceses, Victor Hugo, Lamartine e Vigny será fortemente marcada pelo terror revolucionário que provocou no começo do século XIX um retorno das forças

1 Larissa Drigo Agostinho, mestre em filosofia pela Universidade de Paris I-PanthéonSorbonne e mestre e doutoranda em literatura francesa pela Universidade de Paris IV-Sorbonne é professora convidada do mestrado lato sensu Psicanálise e linguagem: Uma outra Psicopatologia na Pontifícia Universidade Católica de São Paulo. E-mail: larissadrigo@yahoo.com.br. 
conservadoras que pretendiam negar todos os ideais do século XVIII. Trata-se de um movimento estético, moral e político a que se chamou contrarrevolução. O poeta romântico, desta primeira geração, é aquele que procura um retorno ao antigo regime e a reinstauração do catolicismo. Uma geração que Paul Bénichou definiu a partir do termo "sacre de l'écrivain":

Por mais difícil que seja definir através de caracteres constantes a visão romântica do mundo, percebemos que uma certa modificação na fé humanista do século precedente forneceu o essencial, e que no seio desta modificação, mesmo que ela se apresentasse como um compromisso com a fé religiosa, continuava a se desenhar os contornos de um poder espiritual novo. Este poder, residia na literatura, elevada a uma dignidade até então desconhecida. O espiritualismo romântico se inclina na direção de um investimento particular na poesia, neste sentido o romantismo é uma sacralização do poeta. (...) É na exaltação da poesia, colocada na altura do valor mais elevado, que se tornou religião, luz do nosso destino, que devemos ver o traço distintivo do romantismo. ${ }^{2}$ (BENICHOU, 2004, p. 259)

O poeta do primeiro romantismo é o poeta mago, profeta, aquela que fala ao povo em nome de Deus, como guardião de seu destino terrestre e ponte entre o divino e o humano. O poeta é investido de um poder "extraordinário", uma vez que se faz porta-voz dos costumes e tradições nacionais e religiosas, ele é capaz de unificar a nação em torno de uma crença, em torno de um único Deus, como um rei simboliza o poder divino, encarna-o na terra e assim reúne a totalidade do seu reino em torno de sua figura.

"Do Consulado à Restauração, um longo movimento do pensamento conservador exalta a poesia para torná-la o esteio da religão, a reparadora salutar da subversão filosófica" (BENICHOU, 2004, p 131) Por subversão filosófica entenda-se o racionalismo do século XVIII, sua crítica à dogmática religiosa, enfim todo movimento de ideias que transformou o pensamento das Luzes em agente da revolução. Portanto, nos anos 20 do sécul XIX, os jovens românticos, católicos e monarquistas fundam sua poesia na referência religiosa que o movimento da

2 As traduções são da autora. 
contra-revolução exaltava como único meio para restaurar os costumes e tradições banidos da França pela revolução. O romantismo tem sua origem no movimento contrarevolucionário posterior à 1789: "é do seio da contra-revolução que emergiu entre 1800 e 1820 a fonte poética do século XIX. A ideia de um ministério espiritual do poeta, que é a alma da poesia moderna, germinou neste meio; os poetas saíram primeiramente, de lá” (BENICHOU, 2004, p.186.)

É desta poesia que Baudelaire extrai o material de sua lírica, do romantismo católico e conservador que transformou a religião na fonte que garantiu legitimidade aos governos restauradores.

\section{Deus, o diabo e as mulheres}

É justamente nos poemas de temática "amorosa" que Baudelaire destila todo seu veneno contra os ideais românticos. Observemos, por exemplo, o poema "Je t'adore à l'égal de la voûte nocturne" (XXIV), ("Eu te amo como se ama a abóbada noturna").

Eu te amo como se ama a abóbada noturna,

Ó taça de tristeza, ó grande taciturna,

E mais ainda te adoro quanto mais te ausentas

E quanto mais pareces, no ermo que ornamentas,

Multiplicar irônica as celestes léguas

Que me separam das imensidões sem tréguas. ${ }^{3}$ (BAUDELAIRE, 1985, p. 161)

A evocação da mulher amada adorada contrasta com os adjetivos empregados pelo poeta para descrevê-la. O eu lírico compara sua amada a um "vaso", poderia ele ter sido mais cruel e irônico? A mulher é aqui reduzida ao estatuto de um objeto de decoração. Em seguida, ele a qualifica de "grande taciturna". Uma mulher triste, portanto, como uma espécie de zumbi, uma morta-viva, que aparece sempre à noite, para "ornamentar" o poema.

3 "Je t'adore à l'égal de la voûte nocturne,/ Ô vase de tristesse, ô grande taciturne,/ Et t'aime d'autant plus, belle que tu me fuis, / Et que tu me parais, ornement de mes nuits, / Plus ironiquement accumuler les lieues/ Qui séparent mes bras des immensités bleues." BAUDELAIRE, 1999, p. 73) 
Como constatamos nos últimos versos da estrofe citada, o poeta se pergunta se "não é irônico que seu amor aumente com a distância que o separa de sua amada"? Não é irônico que o eu se sinta cada vez mais apaixonado à medida que se sente cada vez mais distante de seu ideal, cada vez mais incapaz de ter em seus braços as "imensidades azuis "? Eis que a mulher adquire seu estatuto ideal, ironicamente distante, e idealizada, ela é inacessível, comparada com o "azur", ou "Ideal”. Assim quando ela finalmente ocupa o lugar que é o seu no imaginário romântico, não sem ironia, pois ao se indagar sobre este ideal, Baudelaire já procura indicar a sua nulidade, eis que ocorre o seu rebaixamento, e se produz o ataque certeiro dos versos/vermes baudelairianos:

Ao assalto me lanço e agito-me na liça,

Como um coro de vermes junto a uma carniça,

E adoro, ó fera desumana e pertinaz,

Até essaalgidezquemaisbelatefaz! ${ }^{4}$ BAUDELAIRE, 1985, p. 161)

O eu lírico avança na direção da mulher sempre distante, e a ataca. Este ataque é dirigido a mulher ideal, comparada as "imensidões azuis" que se torna agora uma "besta" ,um animal, uma "presa". O poeta é comparado a um "coro de vermes" que profana um cadáver, o corpo inerte da mulher idealizada e "querida" por poetas românticos de várias gerações.

Para Vaillant (2007, p. 121) o alvo de Baudelaire seria a frigidez feminina, "Devemos sem duvida entender que a mulher (...) cria a ilusão pela sua ironia de estar a quilômetros de distância de seu parceiro: a ironia qualifica o efeito de distanciamento - portanto, de centralização - induzido pela indiferença" A ironia seria assim, aquela da mulher que frigida se distancia do poeta, é indiferente à ele e ao seu desejo.

Mas poderíamos ir muito mais longe nesta interpretação. Devemos nos perguntar: Contra quem Baudelaire dirige sua ironia? Quem é esta mulher fria e ideal? A ironia em questão não é a da mulher frigida, mas sim aquela que faz com que o amor do poeta aumente com a distância

4 "Je m'avance à l'attaque, et je grimpe aux assauts,/ Comme après un cadavre un chœur des vermisseaux,/ Et je chéris, ô bête implacable et cruelle !/ Jusqu'à cette froideur par où tu m'es plus belle !" (BAUDELAIRE, 1999, p. 73) 
que o separa de seu objeto de desejo. Como se Baudelaire se perguntasse, "não é irônico, e cômico, tantos poetas cantando amores impossíveis, cantando amores que existem apenas em sua imaginação, amores ideais, idealizados, justamente pela distância que separa os amantes"? Esta frieza é na verdade, não a de uma mulher irônica ou frigida, mas a de uma mulher morta, de um ideal feminino romântico que Baudelaire transforma num cadáver em putrefação, que ele ataca como um verme com seus versos.

Esta mulher que para o crítico Vaillant é a mulher-frigida é na verdade a mulher idealizada pelo primeiro romantismo que é identificada com a própria Virgem Maria. Tomemos, por exemplo, o poema de Victor Hugo (1972, p. 166) «À toi » presente na antologia Odes et ballades de 1822, portanto, do primeiro livro do autor, marcado pelo imaginário católico, e pelo conservadorismo político, do jovem e monarquista Victor Hugo.

Este poema foi escrito em comemoração a festa da Virgem, "le jour sacré parmi les jours !’. O eu lírico relembra sua infância, que em Victor Hugo, rima com inocência, ignorância e esperança, onde o eu via apenas a virgem no céu, "belle et pure", aquela que deveria como ele compartilhar uma felicidade sem fim ("partager un bonheur qui ne doit pas finir"). Mas este tempo passou. Hoje "o mal se eleva" ("le malheur s'est levé"). O poeta "órfão", "sem os prantos de sua bem amada" ("sans les pleurs de sa bien-aimé") segue sozinho, uma "lâmpada apagada entre os vivos" (il est chez le vivants comme une lampe éteinte”).

Notamos que a Virgem "bela e pura” é também a bem amada do poeta, ela é também a sua mãe que adquire cada vez mais traços humanos ao longo do poema. O eu clama para que a Virgem embeleze sua vida com seu sorriso, pois "A maior felicidade ainda está no amor" ("Le plus grand bonheur est encore dans l'amour") e a convida a experimentar com o poeta "um casto casamento" ("chaste hymen"). Finalmente, ele pede que ela venha para seus braços sem temor, pois "teu esposo não quer que sua glória/ prejudique sua felicidade" ("ton époux ne veut pas que sa gloire / Retentisse dans son bonheur "). O poema termina com o eu se dirigindo à mulher amada/ a Virgem e declarando que, se arrependerá " gemendo", "aquele que morreu sem reclamar,/”E que te amava com tanto amor!" ("gémissant à son tour", "celui qui mourut sans se plaindre, / Et qui t'aimait de tant d'amour !’). 
Aqui observamos que a mulher fetiche dos românticos é ainda mais adorada quanto mais se assemelha a Virgem Maria, quanto mais distante, portanto, está do poeta, que vê o seu amor ainda aumentado pela possibilidade de uma união casta e pura com essa mulher idealizada. Esta ideal de amor e de mulher, construído a partir do imaginário católico será explorado por Baudelaire em todos seus contornos e desdobramentos. Esta mulher casta será identificada com uma "taciturna", um "vaso de tristeza", enfim uma morta - um cadáver - que o poeta ataca e devora como um verme, com o único intuito de ironizar, desmascarar e rir de uma poética católica que negava a vida e seus prazeres materiais em nome da salvação extraterrena, da felicidade casta, a "voluptuosidade santa" do paraíso celestial.

Constatamos que a trajetória irônica do poema "Je t'adore à l'égal de la voûte nocturne" onde a mulher é idealizada e em seguida rebaixada ao estatuto de cadáver se torna cada mais evidente quando comparamos à poesia de Baudelaire à de Victor Hugo, por exemplo. Isto deixa claro que o alvo da ironia baudelairiana era justamente a poesia do primeiro romantismo. Como se esta mulher fria, fosse não somente o indício da impossibilidade de se alçar este ideal de amor puro, esta mulher que na verdade é um cadáver, simboliza aqui a morte do ideal romântico. Ao transformar um ideal de amor num corpo inerte e em decomposição Baudelaire ataca estes ideais, procura mostrar que o que está verdadeiramente em estado de putrefação neste momento da história são os ideais românticos de pureza, castidade, os ideias católicos que asseguram a manutenção de um imperador que usurpou o poder que lhe foi concedido "democraticamente".

Assim ao rebaixar este ideal romântico é todo o imaginário do romantismo que Baudelaire procura ironizar. A mulher pálida e casta só poderia ser um cadáver, pois todo o amor que não se materializa simplesmente não existe. A negação da realização amorosa, a insistência romântica em manter o amor sempre casto ou impossível, contribui certamente para a afirmação do amor, como um ideal que não encontra lugar sobre a terra, mas para Baudelaire essa negação da vida, este ascetismo católico não passa de uma abstração vã, fora de moda, de uma ideologia em ruínas, que insiste em se perpetuar. Baudelaire quer deixar em evidência o estado de ruínas no qual se encontra o imaginário romântico, que seria absolutamente incapaz de dar conta da experiência dos sujeitos na modernidade. 


\section{Mas afinal, porque o diabo?}

Julles Vallès, crítico literário e jornalista do século XIX, contemporâneo de Baudelaire, escreve, no momento da morte do poeta, no jornal La rue uma dura crítica ao poeta seu contemporâneo, o crítico afirma o seguinte:

Havia nele algo de padre, de velha dama, e do ator. Era sobretudo um ator, mal ator. (...)

Satã, este diabinho, fora de moda, acabado, que ele se colocou como objetivo de cantar, adorar e abençoar! Por quê? Por que o diabo ao invés do bom Deus? É que, vejam vocês, este palhaço da imortalidade, era no fundo um religioso ; não um cético ; ele não era um demolidor, mas um crente ; ele era o niam-niam de um misticismo besta e triste, no qual os anjos tem asas de morcego e rostos de meninas; eis o que ele inventou para nos chocar, este Jeune France velho demais, esta criança livre pensadora. (VALLES, In : BAUDELAIRE, 1975, p. 971-973, negrito nosso)

Esta crítica é muito importante, uam vez que além de nos revelar que o satanismo, em meados da metade do século XIX não tinha nada de chocante, pelo contrário não passava de um lugar-comum desgastado da poesia francesa, nos mostra também que a pior acusação que poderia ser feita a um poeta neste período era justamente compará-lo aos poetas católicos do começo do século. Por que o crítico para desqualificar a poesia baudelairiana atribui a ela total ausência de originalidade devido ao seu caráter "religioso".

O texto já nos fornece um caminho interpretativo, antes de mais nada, o recurso ao satanismo não tinha como intuito o choque, assim ele deixa evidente que a agressividade da poesia baudelairiana não era gratuita, e isso nos coloca diante da questão de saber por que, mesmo sabendo que o satanismo já estava fora de moda em seu tempo, Baudelaire decide, apesar deste fato, utilizar esta temática em sua poesia. Devemos nos perguntar que função teria esse recurso que longe de chocar seus contemporâneos os deixaria na verdade entediados ao ter diante dos olhos nada além de um desgastado clichê? 
Em seu Baudelaire Sartre afirma que Baudelaire faz o Mal de maneira consciente, e justamente por ter consciência do mal que ele praticava, afirma na verdade, sua adesão ao Bem. Para Sartre ao querer fazer o contrário do Bem, Baudelaire afirma e conserva a ordem que ele pretende negar. Assim a moral baudelairiana parece ser o último recurso racional que procura evitar a confrontação com a verdadeira natureza, fictícia da moral. O hipócrita seria assim um homem satânico, um pecador, aquele que faz o contrário do Bem, conscientemente e que sente um verdadeiro prazer na culpa, no remorso, na martirização na qual a ação maldosa the engaja.

Mas o que Baudelaire procura ao ironizar os ideais românticos, é evidenciar a falência moral de seu tempo expondo suas contradições, demonstrando o caráter hipócrita desta moral que mesmo ao fazer o mal afirma o bem supremo, clama por redenção, nega a vida e se mantém pregando ideais absurdos. A ironia, esta que permite ultrapassar a dicotomia entre o bem e o mal só é possível a partir da reivindicação de autonomia da poesia que se faz justamente a partir de sua desobrigação com relação a moral:

"Eu digo que se um poeta persegue um objetivo moral, ele diminuiria a força de sua poesia, não é imprudente apostar que sua obra será ruim. A poesia não pode, sob pena de morte, se assimilar à ciência ou a moral; ela não tem a verdade por objeto, ele só tem a si mesma" (BAUDELAIRE, 1976, p. 628, negrito nosso)

Esta independência da arte com relação a moral nos permite justamente pensar a moral, como Nietzsche também pretendia, como uma mentira, uma ficção. No Salão de 1859, capítulo cinco, intitulado, "Religião, historia, fantasia" Baudelaire anuncia como devemos compreender a moral presente numa obra de arte: "Digamos, portanto simplesmente que a religião, sendo a mais elevada forma de ficção do espírito humano (eu falo propositadamente como falaria um professor ateu de belas artes, e nada deve ser concluído contra a minha fé)." (BAUDELAIRE, 1976, 628, negrito nosso) Em seguida, ele explica que o poeta, um comediante, um artista "acreditam na realidade do que representam, porque são acalentados pela necessidade", por isso a arte é o único domínio onde o homem pode dizer " eu acredito se quiser, se eu não quiser, eu não acreditarei”. (BAUDELAIRE, 1976, 629) 
Um hipócrita, dissimula, mente, age contrariamente aos princípios e ideias dos quais fala. E o que faz um poeta? Não é esta, a arte mesma de escrever: mentir? Dissimular? Tornar-se outro ?

Não é assim que Fernando Pessoa define o poeta, como um fingidor ? Um fingidor que finge tão bem que chega a fingir que é dor a dor que deveras sente? Como quem diz que a verdadeira arte da poesia consiste em criar uma mentira convincente.

Mas Baudelaire não quer convencer e por isso confessa sua hipocrisia, a ironia de sua arte está no desejo de expô-la justamente como uma mentira, uma dissimulação, ele não quer convencer não quer esconder nada, quer expor a mentira que sustenta a sua arte, quer expor a verdade do material a partir do qual ele cria, que é a temática do primeiro romantismo francês.

A ironia de Baudelaire que é a mentira desvelada, a arte que se assume enquanto mera aparência exprime e desvela a contradição entre a ação e o enunciado, entre o imaginário romântico e o baudelairiano onde o primeiro aparece em estado de putrefação. A ironia abre uma fissura entre o real e o ideal, entre o conjunto das ideias românticas a realidade cotidiana, que o poeta assim como seus leitores hipócritas conhecem bem. A ironia denuncia a distância entre o ideal e o real, e instaura uma desconfiança com relação a esses ideais, que parecem ironicamente cada vez mais puros quando comparados à imundice e miséria do mundo prostituído no qual o poeta parece diabolicamente mergulhado. O que Baudelaire quer não é simplesmente chocar seus leitores, mas levá-los a desconfiar de um imaginário literário que os faz viver inexoravelmente na mentira.

Por isso Baudelaire recorre ao cômico. O próprio Baudelaire nos deixou um tratado sobre a essência do riso, um artigo que atesta a importância da questão em sua obra, uma questão e o poeta confessa ter se tornado "uma obsessão". Ele tem como título "De l'essence du rire et généralement du comique dans les arts plastiques".

Neste texto Baudelaire define o riso a partir de sua dimensão diabólica como contrário às disposições dos sábios, (o sábio ri tremendo) entenda-se aqui, por exemplo, Virginie, o sábio, a moça casta, ele é aquele que é incapaz de rir, que nos mostra a força demolidora do riso. 
Rir da moral, rir dos costumes e de um sistema de valores é muito mais do que simplesmente criticá-los.

O riso é próprio dos espíritos superiores, ele implica uma certa superioridade do homem que ri em relação ao que provoca o seu riso. Por isso o riso demonstra a insignificância do que nos faz rir, ele denigre, rebaixa, desqualifica. Mas o riso é também o resultado da própria insignificância humana. Ele se situa entre estes dois extremos, por isso ele é também diabólico, porque o riso é essencialmente humano, ele se situa entre a grandeza divina e a baixeza animal. Esta oscilação é que nos faz rir, rimos das nossas pretensões de grandeza assim como da nossa mediocridade.

Rindo Baudelaire não apenas instaura uma desconfiança com relação ao sistema de valores de seu tempo, expondo suas contradições, ele pode, através do riso dissolvê-las, rindo da sua incoerência é todo o edifício moral que se abala, que desvela sua hipocrisia, que se mostra como uma mentira, mera aparência.

Ao rir de seu tempo, dos costumes e da moral cristã que limitava a experiência poética moderna, Baudelaire indica um novo horizonte para o qual a poesia deveria se abrir. Nela o romantismo aparece como um clichê degradado, risível, rebaixado, exposto em toda a sua insignificância.

Com Baudelaire a poesia se desprende das antigas formas de expressão da subjetividade e da gramática religiosa dos afetos, (que mantém as relações amorosas enclausuradas pelas oposições entre amor/sexo, corpo/ alma, ideal/ spleen, pecado/redenção etc.) ela se desprende do jogo de poder entre submissão e dominação, se libera de toda obrigação moral (se desliga do Bem como do Mal, de Deus como de Satã). Um passo decisivo na configuração da arte autônoma, aquela que não pretende ensinar, educar ou oferecer redenção, mas ser o veículo de expressão e renovação do próprio presente, oferecer aos seus leitores uma arte na qual eles possam não apenas se identificar, mas ir além de si mesmos.

A partir deste momento, uma outra modernidade poderá surgir, a que Baudelaire anuncia em seu Peintre de la vie moderne, este momento em que a arte autônoma, liberada de toda e qualquer obrigação moral, se dedicaria a extrair o que há de eterno e imutável no fugídio e fugaz presente. 


\section{Bibliografia}

BAUDELAIRE. CEuvres complètes II. Paris : Gallimard, 1976.

Les fleurs du mal. Paris : LGF, 1999.

As Flores do mal. Trad : Ivan Junqueira, Rio de Janeiro:

Nova Fronteira, 1985.

HUGO, V. Poésie. Paris : Seuil, 1972.

SARTRE, J-P. Baudelaire. Paris: Gallimard, 1975.

VAILLANT, A. Baudelaire, poète comique. Rennes: Presses universitaires de Rennes, 2007.

VALLES, J. «Charles Baudelaire », La rue, 7 septembre 1867, In :

Baudelaire, Guvres, R. Bellet ed., t. I, Paris : Gallimard, "Bibliothèque de la Pléiade ", 1975.

\section{Imagem:}

Disponível em http://1.bp.blogspot.com/-Qpuvx1oDQVA/Tl2W70Ny3sI/ AAAAAAAAIw4/Hc_wjVrr0Zk/s400/baudelaire888\%25281\%2529.jpg, consultado em $07 / 10 / 2012$ 
